\title{
C3-BIOECONOMY
}

Circular and Sustainable Bioeconomy

\section{Uso de biofertilizantes para una producción más rentable y sustentable de caña de azúcar en México, Biofábrica Siglo XXI}

\author{
Paula Medina Morales ${ }^{1}$, César González Monterrubio ${ }^{1}$ y Marcel Morales Ibarra ${ }^{1}$
}

Autor de Correspondencia: paula.medina@biofabrica.com.mx

\section{Resumen:}

El actual modelo de producción agrícola, herencia de la llamada 'revolución verde' que tuvo lugar durante la segunda mitad del Siglo XX, es un modelo que muestra claros síntomas de agotamiento, debido a que es un modelo caro, ineficiente y altamente contaminante. Dicho modelo permitió el incremento de la producción agrícola, pero con un alto costo ecológico, ya que los agroquímicos utilizados, en particular los fertilizantes, son muy ineficientes y altamente contaminantes. En la búsqueda de alternativas que puedan dar respuesta a los retos que enfrenta la producción agrícola, en los últimos años se han desarrollado soluciones biológicas utilizando la agrobiotecnología. Un ejemplo de estos desarrollos son los biofertilizantes, cuya base es el uso de microorganismos vivos para la nutrición y desarrollo de los cultivos, así como el mejoramiento de la fertilidad de los suelos.

La empresa mexicana, Biofábrica Siglo XXI, lleva dos décadas desarrollando alternativas agro biotecnológicas para promover un sistema de producción agrícola más eficiente y ecológico. En la caña de azúcar han logrado: 1) incrementar productividad; 2) aumentar utilidad del productor; 3) reducir hasta 75\% la aplicación de fertilizantes químicos; 4) mejorar la vida microbiana del suelo; 5) aumentar el desarrollo radicular; 6) mayor captura de carbono.

Palabras clave: biofertilizantes, agricultura, sustentabilidad, biotecnología, bioeconomía

\section{Use of biofertilizers for a more profitable and sustainable sugarcane production in Mexico, Biofábrica Siglo XXI}

\author{
Paula Medina Morales ${ }^{1}$, César González Monterrubio ${ }^{1}$ y Marcel Morales Ibarra ${ }^{1}$
}

\section{Abstract:}

The current model of agricultural production, inherited from the so-called 'green revolution' that took place during the second half of the 20th century, is a model that shows clear symptoms of depletion, because it is an expensive, inefficient and highly polluting model. This model allowed an increase in agricultural production, but with a high ecological cost, since the agrochemicals used, particularly fertilizers, are very inefficient and highly polluting. In the search for alternatives that can respond to the challenges faced by agricultural production, in recent years, biological solutions have been developed using agrobiotechnology. An example of these developments are biofertilizers, whose basis is the use of live microorganisms for the nutrition and development of crops, as well as the improvement of soil fertility.

\footnotetext{
1 Biofábrica Siglo XXI. México
}

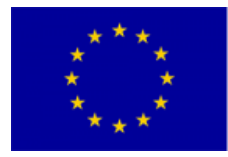

UNIÓN EUROPEA

PROYECTO COFINANCIADO POR ELFONDO EUROPEO D DESARROLLO R
(FEDER) Una manera de hacer Europa

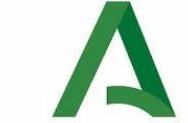

Junta de Andalucía
Andalucía

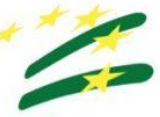

se mueve con Europa 
The Mexican company, Biofábrica Siglo XXI, has been developing agro-biotechnological alternatives for two decades to promote a more efficient and ecological agricultural production system. In sugarcane, they have managed to: 1) increase productivity; 2) increase producer profit; 3 ) reduce the application of chemical fertilizers up to $75 \%$; 4) improve soil microbial life; 5) increase root development; 6) increased carbon sequestration.

Keywords: biofertilizers, agriculture, sustainability, biotechnology, bioeconomy

\section{INTRODUCCIÓN}

El cultivo de la caña de azúcar está considerado entre los más importantes a nivel mundial, tanto por su enorme relevancia dentro de la alimentación humana, como por su sobresaliente capacidad de adaptación y elevado nivel de productividad. En México, la agroindustria de la caña tiene una gran importancia en el desarrollo económico y social del país. México es el sexto productor de caña a nivel mundial, produciendo más de 56 millones de toneladas anuales. Según datos de la Secretaría de Agricultura y Desarrollo Rural del 2020, la caña de azúcar se cultiva en 848 mil hectáreas en 22 Estados de la república mexicana. Se calcula que están involucrados alrededor de 200 mil productores, de los cuales, el $98 \%$ son pequeños productores, los cuales, tienen menor acceso a nuevas tecnologías y capacitación sobre mejores prácticas agrícolas.

El actual sistema de producción de caña se basa en el modelo de producción impulsado por la Revolución Verde que tuvo lugar a mediados del siglo XX, basado principalmente en el uso de grandes cantidades de agroquímicos. Dicho modelo permitió incrementar el rendimiento, pero con un alto costo ecológico, "a partir de 1990, los efectos negativos de la Revolución Verde empezaron a reflejarse con la pérdida de la biodiversidad agrícola y el uso indiscriminado de productos químicos" (Reyes, 2011). A pesar de que desde el año 2005 existe la Ley de desarrollo sustentable de la caña de azúcar en México, la cual establece normas para el desarrollo sustentable del cultivo, introduciendo disposiciones relativas a los procesos de siembra, cultivo, cosecha, industrialización y comercialización, la realidad es que hoy en día se siguen llevando a cabo prácticas altamente nocivas y contaminantes en su producción. Entre las más comunes se encuentran el monocultivo, el uso excesivo de agroquímicos, uso intensivo de maquinaria que acelera la 
compactación del suelo, quema del cultivo para facilitar la cosecha, poco o nulo tratamiento de los residuos, malas prácticas de riego, entre otras. Aunado al deterioro ambiental, estas problemáticas ponen en riesgo la seguridad y soberanía alimentaria del país, así como el modo de subsistencia no solo de los productores, sino de miles de personas que trabajan directa o indirectamente a lo largo de la cadena productiva - "la industria agroalimentaria de la caña de azúcar emplea al 13.3\% de la población ocupada a nivel nacional (más de siete millones de personas)"-(Falcón, 2018).

Si hablamos de los impactos sociales del actual modelo agrícola, podemos resaltar los elevados costos de producción y los riesgos para la salud de los trabajadores al estar expuestos a grandes cantidades de agroquímicos. Según la clasificación de la Organización Mundial de Salud sobre productos químicos peligrosos utilizados en la agricultura, se pueden clasificar en cancerígenos (pueden provocar cáncer), neurotóxicos (pueden dañar el cerebro) o teratógenos (pueden dañar al feto).

Por todos estos motivos, resulta indispensable promover un modelo de producción basado en la sustentabilidad y el conocimiento científico, que incluya el uso de nuevas tecnologías, la incorporación de mejores prácticas agrícolas, la comprensión y el conocimiento de los ecosistemas y el respeto por los recursos naturales.

La empresa mexicana Biofábrica Siglo XXI, surgida en 2013 a partir de un convenio de licencia tecnológica celebrado con el Centro de Ciencias Genómicas de la Universidad Nacional Autónoma de México, lleva más de 18 años vinculando la investigación, innovación y desarrollo tecnológico, con la producción agrícola, con el objetivo de ofrecer alternativas productivas que permitan cambiar el modelo agrícola actual por uno más ecológico, rentable y sustentable.

El presente artículo muestra los resultados obtenidos con el uso de biofertilizantes en la producción de caña de azúcar, que demuestran que, con 
el uso de estos bioinsumos, se mejoran sustancialmente la sustentabilidad y rentabilidad del cultivo.

\subsection{Uso de la agrobiotecnología como alternativa al actual modelo de producción agrícola}

"Uno de los requerimientos más importantes de los cultivos es el mantenimiento de la fertilidad del suelo. Tradicionalmente, la deficiencia de nutrimentos, especialmente de Nitrógeno, es corregida a través de la adición de fertilizantes. Sin embargo, los altos costos limitan su uso, sobre todo en los países en desarrollo, donde la necesidad de incrementar la producción de alimentos es más urgente. Por otro lado, se estima que los cultivos absorben entre un 20 a un $40 \%$ del fertilizante aplicado, el resto se pierde por diversos mecanismos, generando cuantiosas pérdidas económicas y contaminación ambiental" (Grageda, et al. 2012), tales como la eutrofización de cuerpos de agua, la salinización y acidificación del suelo, el deterioro de las condiciones microbiológicas del suelo, emisión de Gases de Efecto Invernadero (GEI) —en el caso de los fertilizantes nitrogenados, se calcula que, por cada kilo aplicado de estos insumos, se emiten 12 kilos de bióxido de carbono a la atmósfera, considerando su producción, traslado y aplicación (Yara International, 2010)—entre otros.

Una de las alternativas de nutrición vegetal más rentables y seguras que existen actualmente, son los llamados biofertilizantes, que son productos biológicos hechos a base de microorganismos benéficos que ayudan a las plantas y al suelo en diversos procesos biológicos, como la estimulación del crecimiento vegetativo, la solubilización y transporte de nutrientes, la protección de las raíces contra plagas y enfermedades, así como al mejoramiento y regeneración de los suelos agrícolas.

En el caso de estudio del presente artículo, se utilizaron biofertilizantes formulados con la bacteria Azospirillum brasilense y un consorcio de hongos micorrízicos. A. brasilense es "una bateria que crece en estrecha asociación con las raíces de varias plantas. Esta bacteria utiliza los nutrientes excretados por las plantas y a su vez fija el nitrógeno de la atmósfera" (Tortora, et al., 2007). Desde 
que fue descubierta en 1925, se ha comprobado que A. brasilense es una rizobacteria capaz de promover un "mayor crecimiento vegetal en los componentes morfológicos y fisiológicos del rendimiento" (Licea, et al., 2020). Por su parte, las micorrizas forman una asociación mutualista con las raíces de las plantas. "En esta asociación, la planta le proporciona al hongo carbohidratos (azúcares, producto de su fotosíntesis) y un microhábitat para completar su ciclo de vida; mientras que el hongo, a su vez, le permite a la planta una mejor captación de agua y nutrimentos minerales con baja disponibilidad en el suelo (principalmente fósforo), así como defensas contra patógenos" (Camargo, et al., 2012). Con el uso de micorrizas "la fertilización química aplicada puede disminuirse de un 50 a 80\%, ya que la Micorriza mejora la absorción de nutrientes del suelo" (Guerra, et al., 2008).

La empresa Biofábrica Siglo XXI viene promoviendo el uso de biofertilizantes basados en estos y otros microorganismos benéficos en diversos cultivos y regiones de México. En el caso de la caña de azúcar, la empresa lleva trabajando más de una década con la aplicación de biofertilizantes, evaluando sus resultados desde el punto de vista de la productividad, la calidad de la producción, el uso eficiente del fertilizante químico y el mejoramiento de las condiciones físicas, químicas y biológicas del suelo.

A continuación, se expone el caso de una parcela de caña de azúcar ubicada en la localidad de Zacatepec, en el Estado de Morelos, México, en la que se han aplicado biofertilizantes los últimos ocho años. La metodología de seguimiento y evaluación incluye mediciones productivas y económicas, así como de regeneración del suelo, en las que se miden sus propiedades físicoquímicas y microbiológicas, así como indicadores ecológicos como la captura de carbono.

\section{MÉTODO / DESARROLLO DE LA EXPERIENCIA DE INNOVACIÓN}

\subsection{Datos de la parcela}

- Ubicación: Campo La Victoria, Zacatepec, Morelos (México). 
- Precipitación: 599 mm.

- Altura: 910 msnm.

- Clima: Cálido sub húmedo.

- $\quad$ Temperatura media: $24.3^{\circ} \mathrm{C}$.

- Temporal/Riego: Riego por gravedad.

- Fecha de siembra: Noviembre, 2013.

- Variedad: CP_722086.

- Tiempo de seguimiento: 7 años (2014-2021).

\subsection{Materiales y métodos}

- Biofertilización:

- Maxifer (bacteria Azospirillum brasilense).

- Micorrizafer Plus (consorcio de hongos micorrízicos).

- Fertilización: mezcla física 270-67.5-45.

Tratamientos:

- Testigo: 100\% fertilizante químico (1 ton/ha).

- Con biofertilizantes:

- Plantilla (siembra): 50\% Fertilización nitrogenada (135-70-70 1 ton/ha), $1 \mathrm{~L}$ de Maxifer y $3 \mathrm{Kg}$ de Micorrizafer por hectárea.

- Socas: 75\% Fertilización nitrogenada (200-70-70 1 ton/ha), 1L de Maxifer y $3 \mathrm{Kg}$ de Micorrizafer por hectárea.

\subsection{Metodología de evaluación}

Evaluación del incremento en rendimiento y productividad:

- Rendimientos.

- Ingreso neto del productor.

- Producción de biomasa.

- Uso eficiente del fertilizante químico.

Evaluación de la regeneración del suelo:

- Propiedades físicas, químicas y biológicas del suelo: 
- Evaluación de diversidad y abundancia de microorganismos importantes para el suelo y el cultivo.

- Glomalina.

- Estructura del suelo.

Evaluación de los beneficios ecológicos:

- Mitigación del cambio climático:

- Incremento de materia orgánica.

- Secuestro de carbono en el suelo.

\section{RESULTADOS}

\subsection{Evaluación del incremento en rendimiento y productividad}

\subsubsection{Rendimientos}

La caña es un cultivo perenne que se siembra a partir de semilla de otra caña, y esta plantación se explota durante varios ciclos, hasta que la cepa deja de dar rendimientos rentables para el productor y éste decide sembrar nuevamente. Uno de los resultados más importantes en este sentido fue el aumento de la vida útil del cultivo, ya que la parcela biofertilizada lleva ocho cortes (socas) con buenos rendimientos. Cabe mencionar que la vida media de una parcela de caña en el estado de Morelos es de cuatro cortes, esto significa que la parcela con biofertilizantes ya ha duplicado la vida media del cultivo y, dado los buenos rendimientos que sigue obteniendo, el productor la dejará produciendo al menos 3 o 4 ciclos más. En cuanto a los resultados en rendimiento, la parcela con biofertilizantes arroja mejores rendimientos desde el primer año de su aplicación. En promedio, durante los siete ciclos de seguimiento ha obtenido un $30 \%$ más de rendimiento con respecto al testigo (148 vs. 105 ton/ha respectivamente). Cabe resaltar que en el tratamiento con biofertilizantes se hizo una reducción del 30\% de la fertilización nitrogenada, lo que se traduce en menores costos de producción (ver gráfica 1). 
Gráfica 1. Resultados en rendimiento de caña de azúcar.

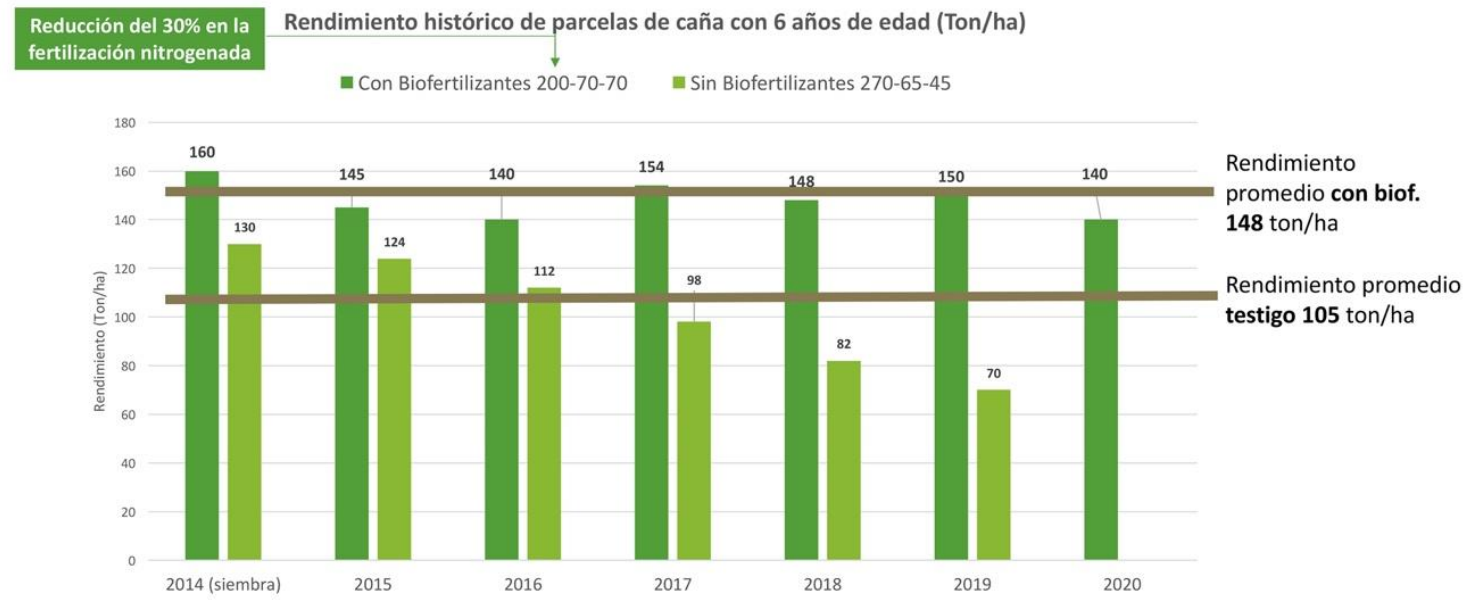

Fuente: Elaboración propia.

Figura 1. Comparativo de ambas parcelas al sexto corte (2019). A la izquierda: parcela con biofertilizantes, a la derecha: parcela testigo.

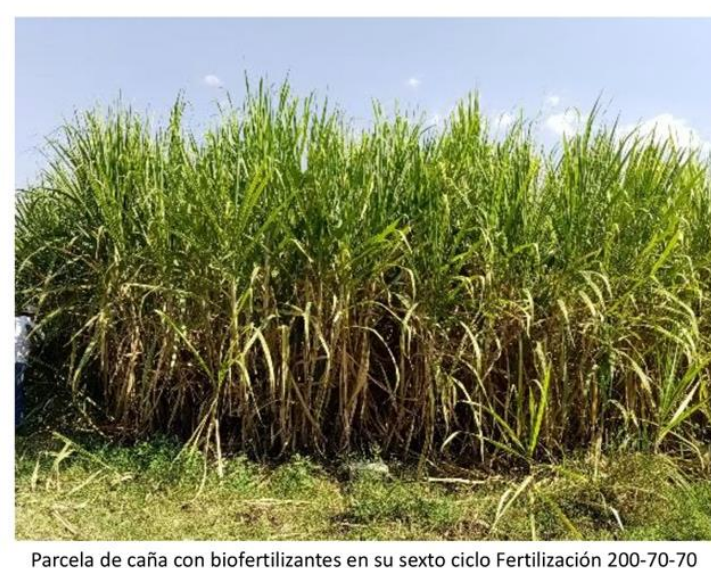

Rendimiento final $150 \mathrm{Ton} / \mathrm{Ha}$

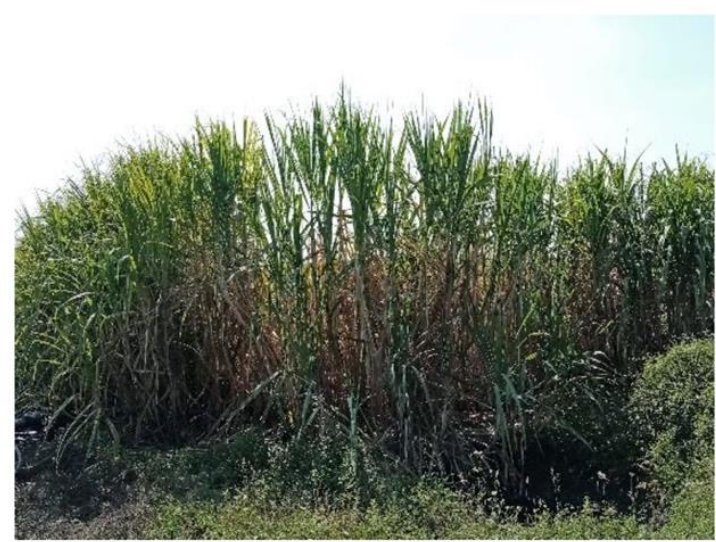

Parcela de caña vecina sin biofertilizantes Fertilización 270-67.5-45

Rendimiento final $70 \mathrm{Ton} / \mathrm{Ha}$

Fuente: Elaboración propia.

\subsubsection{Ganancia neta del productor}

Los principales beneficios que obtiene el productor, es la obtención de una mayor ganancia neta. Como se puede ver en la gráfica 2, la parcela con biofertilizantes arroja mayores ganancias al productor desde el primer año, esto debido al aumento en rendimientos y a una disminución de los costos de producción, proveniente de la reducción en la aplicación de fertilizante químico. A lo largo de los siguientes ciclos la parcela testigo va reduciendo sus 
rendimientos, manteniendo los mismos costos de producción, por lo tanto, el ingreso del productor va disminuyendo en cada ciclo. En cambio, la parcela con biofertilizantes mantiene sus rendimientos, por lo que la ganancia del productor se mantiene en los mismos niveles. Cuando llega el final del sexto ciclo, el productor de la parcela testigo decide plantar una nueva caña, lo que aumenta de manera sustancial los gatos de producción. Si promediamos la ganancia neta de ambos productores, se obtiene que la parcela con biofertilizantes obtuvo más del doble de ganancia con respecto a la parcela testigo.

Gráfica 2. Comparativo de ganancia neta.

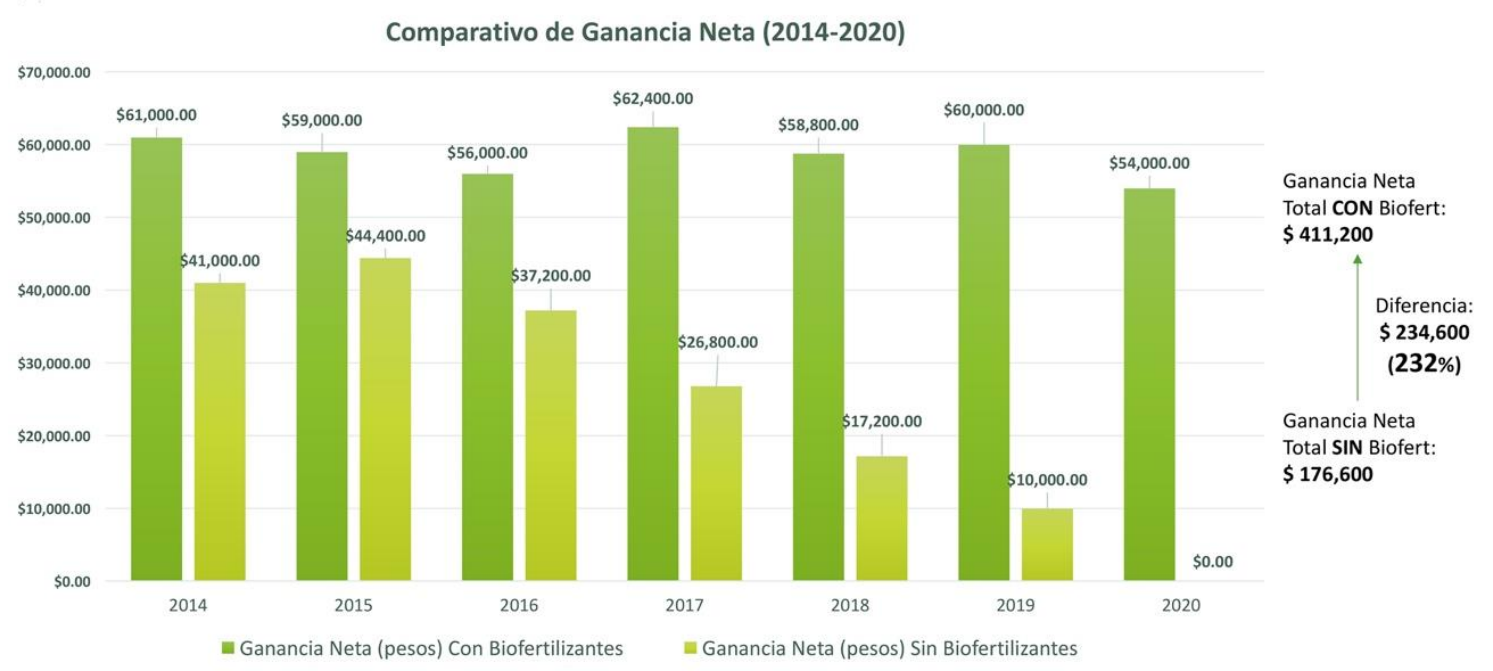

Fuente: Elaboración propia.

En cuanto a los beneficios sociales de adoptar formas de producción más sustentables, además de un aumento en los ingresos de los productores, también podemos mencionar la serie de certificaciones de producción orgánica o sustentable a las que los productores pueden acceder sustituyendo el uso de agroquímicos por bioinsumos. En el caso de la caña de azúcar, la más importante es la certificación Bonsucro, la cual ofrece una prueba de que la producción de caña de azúcar y la cadena de suministro satisfacen requisitos estrictos que abarcan desde indicadores medioambientales, hasta indicadores sobre los derechos laborales y otros factores humanos que afectan al impacto de la producción en la población local. Actualmente, la mayoría de las grandes 
empresas demandantes de azúcar en México y a nivel mundial, como Coca Cola, Nestlé, entre otras; están requiriendo que sus proveedores cuenten con esta $u$ otras certificaciones de producción sustentable. Además, los productores pueden acceder a esquemas de ingresos adicionales como la venta de bonos de carbono o créditos Bonsucro.

\subsubsection{Producción de Biomasa}

En el caso del cultivo de caña prácticamente se cosecha toda la biomasa producida en la parte aérea, así que tradicionalmente lo único que queda como retribución de materia orgánica al suelo es la raíz. Como se puede observar en la gráfica 3, con el uso de biofertilizantes no sólo se incrementó la producción de caña, también se incrementó la biomasa radicular en un 326\%, estas son más de 40 toneladas de biomasa que se quedan como aporte de materia orgánica al suelo.

Gráfica 3. Producción de biomasa en raíz y caña.

Producción de raíz y caña (Ton/Ha)

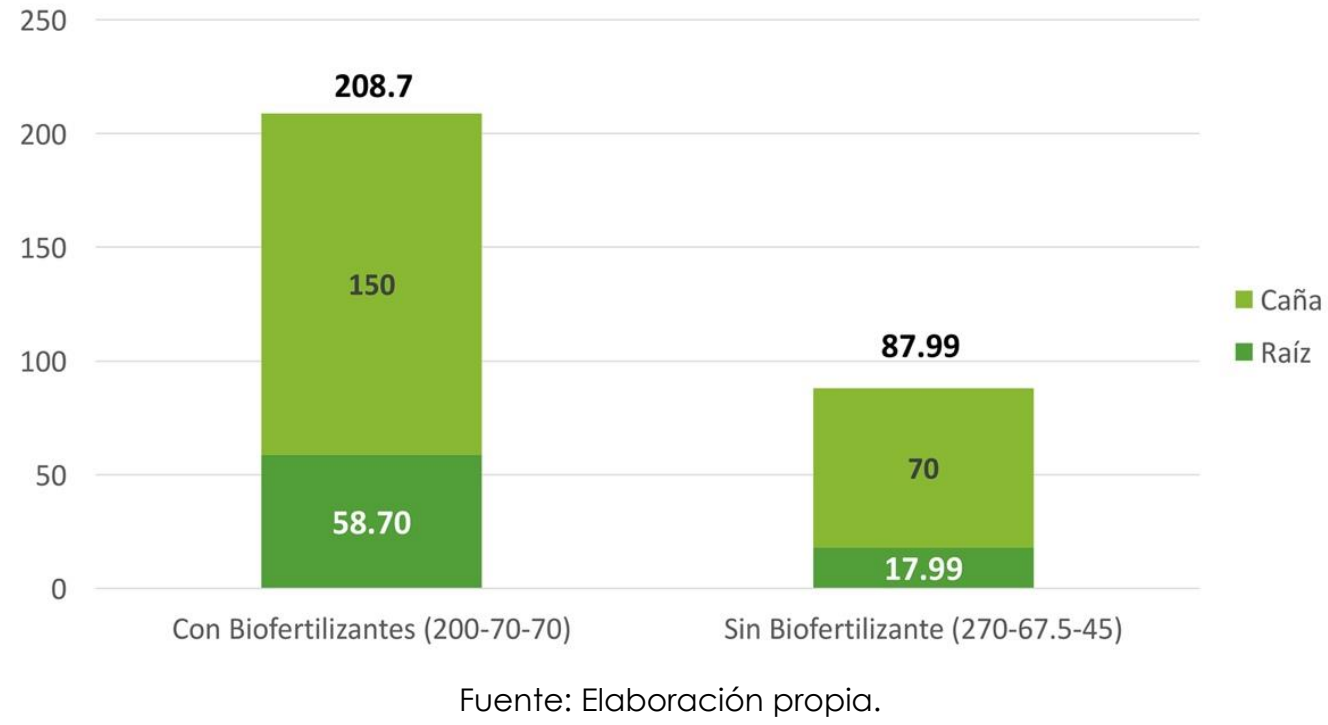

3.1.4 Eficiencia en el uso de fertilizantes químicos

Para estimar este efecto se analizó el porcentaje de nitrógeno (N), fósforo (P) y potasio $(K)$ en el tejido del cultivo, tanto en tallo como en raíz, este porcentaje se multiplicó por la biomasa dando como resultado los kilogramos de estos nutrimentos que logró acumular el cultivo en sus tejidos. 
Cuando comparamos los kilogramos de nitrógeno que tiene el cultivo, con los kilogramos de nitrógeno aplicados como fertilizante se puede observar que, con el uso de biofertilizantes, el cultivo obtuvo poco más del doble (ver gráfica). Por el contrario, el testigo únicamente fijó $169 \mathrm{~kg}$ frente a los 270 aplicados, es decir sólo aprovecho el $62 \%$ del $\mathrm{N}$ aplicado.

Este efecto se deriva de la capacidad de Azospirillum brasilense de fijar nitrógeno, y de la capacidad de los hongos micorrízicos de explorar el suelo y acarrear nutrientes y agua, permitiendo así aprovechar mejor el $\mathrm{N}$ de origen químico y el $\mathrm{N}$ del suelo. Por el contrario, sin el uso de biofertilizantes, si consideramos que también hay nitrógeno en el suelo la eficiencia real del fertilizante aplicado es menor al $62 \%$ aquí reportado.

Gráfica 4. Eficiencia en el uso de Fertilizantes (Nitrógeno).

Eficiencia en el Uso del Nitrógeno (kg/ha)

( $N$ aplicado como fertilizante VS. $\mathrm{N}$ en cultivo)

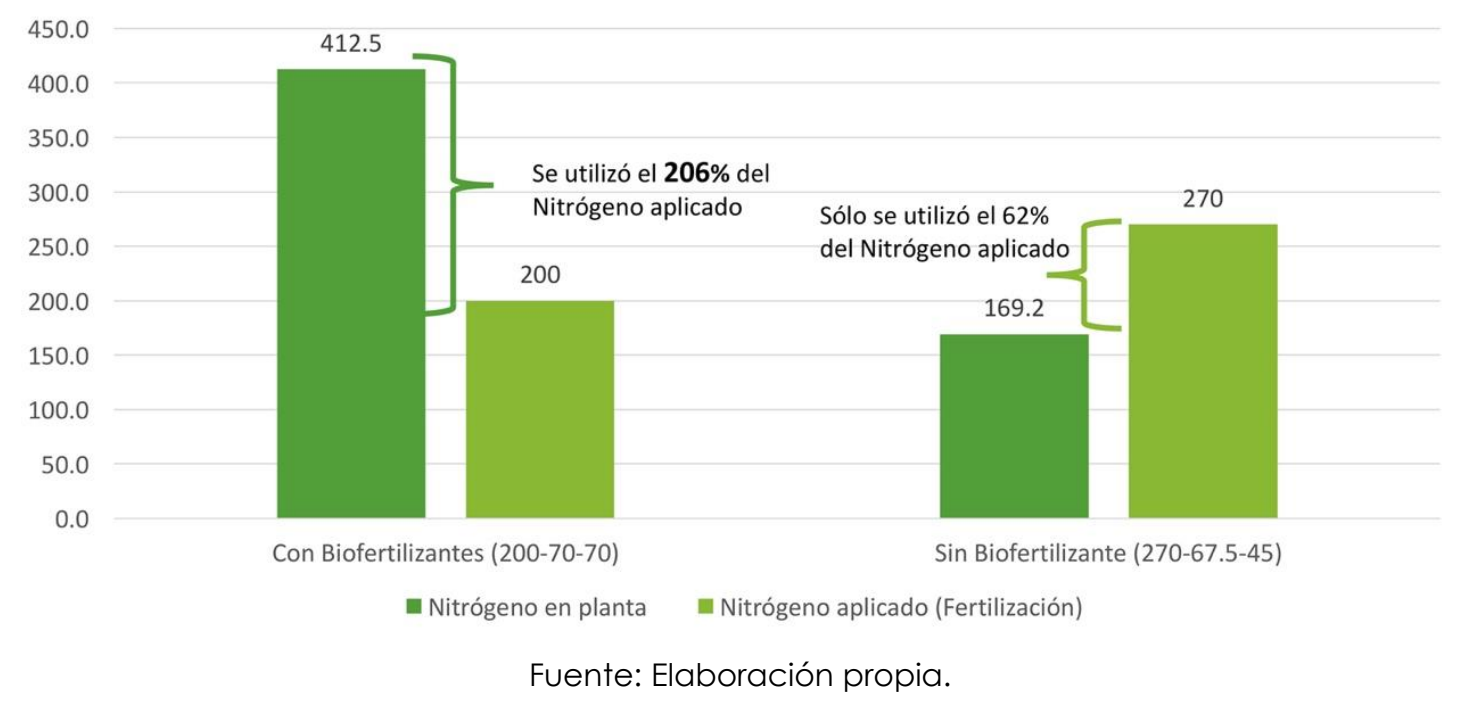

En el caso del fósforo sucede algo similar (ver gráfica 5). Con el uso de biofertilizantes el cultivo obtuvo un $145 \%$ del $\mathrm{P}$ en relación al aplicado como fertilizante químico, mientras que sin biofertilizantes solo obtuvo un $58 \%$ en relación al P de origen químico. Esto sucede porque los hongos micorrízicos permiten aprovechar mejor el fósforo químico y adicionalmente son capaces de aprovechar el fósforo de difícil disponibilidad, permitiendo así aprovechar mejor los recursos del suelo. 
Gráfica 5. Eficiencia en el uso de Fertilizantes (Fósforo).

Eficiencia en el Uso del Fósforo P ( $\mathrm{kg} / \mathrm{ha})$

( $P$ aplicado como fertilizante VS. $P$ en cultivo)

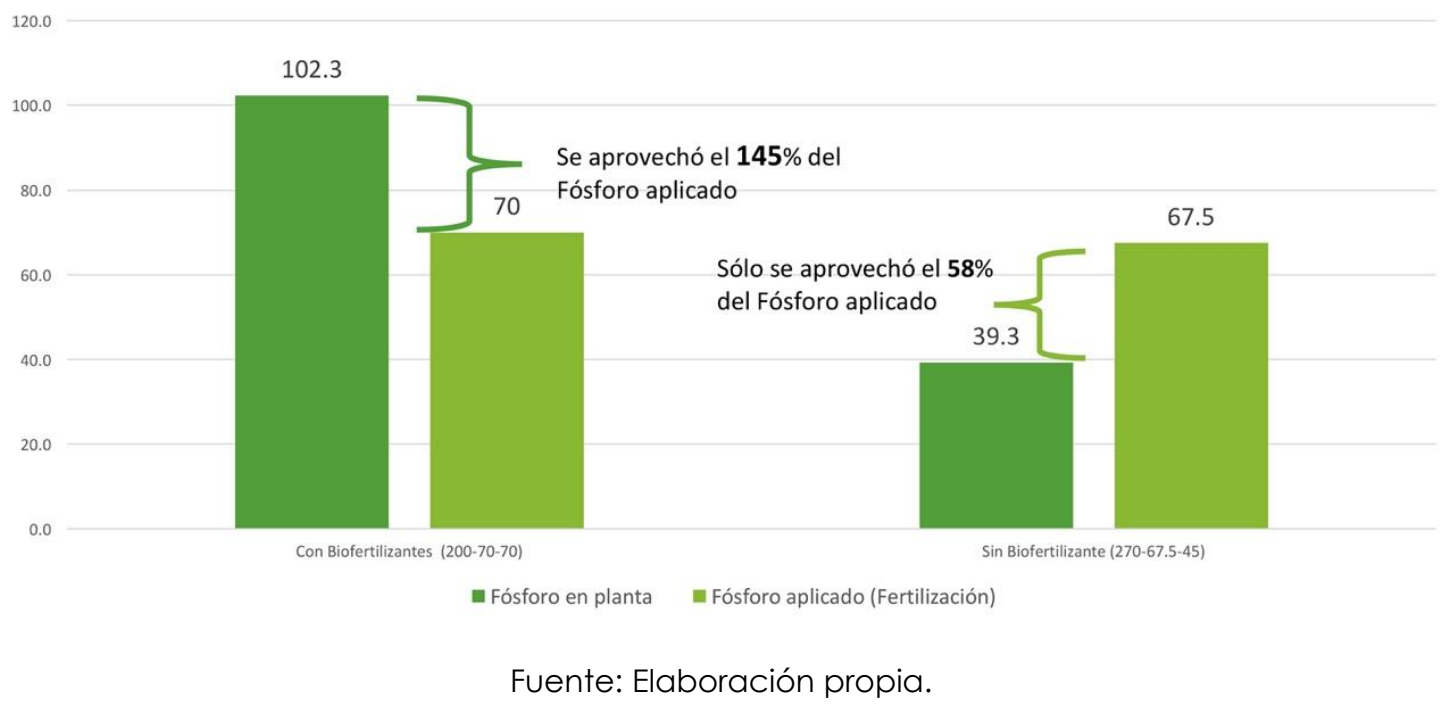

En el caso del potasio se aprecia un efecto algo diferente, ya que el cultivo de caña tiene altos requerimientos de este nutrimento, y, en este caso, el suelo es capaz de proveer la mayor parte de ellos. Aun así, el tratamiento con biofertilizantes logró obtener más del doble del potasio que el tratamiento testigo.

Gráfica 6. Eficiencia en el uso de Fertilizantes (Potasio).

Eficencia en el Uso del Potasio K ( $\mathrm{kg} / \mathrm{ha}$ )

(K aplicado como fertilizante VS. K en cultivo)

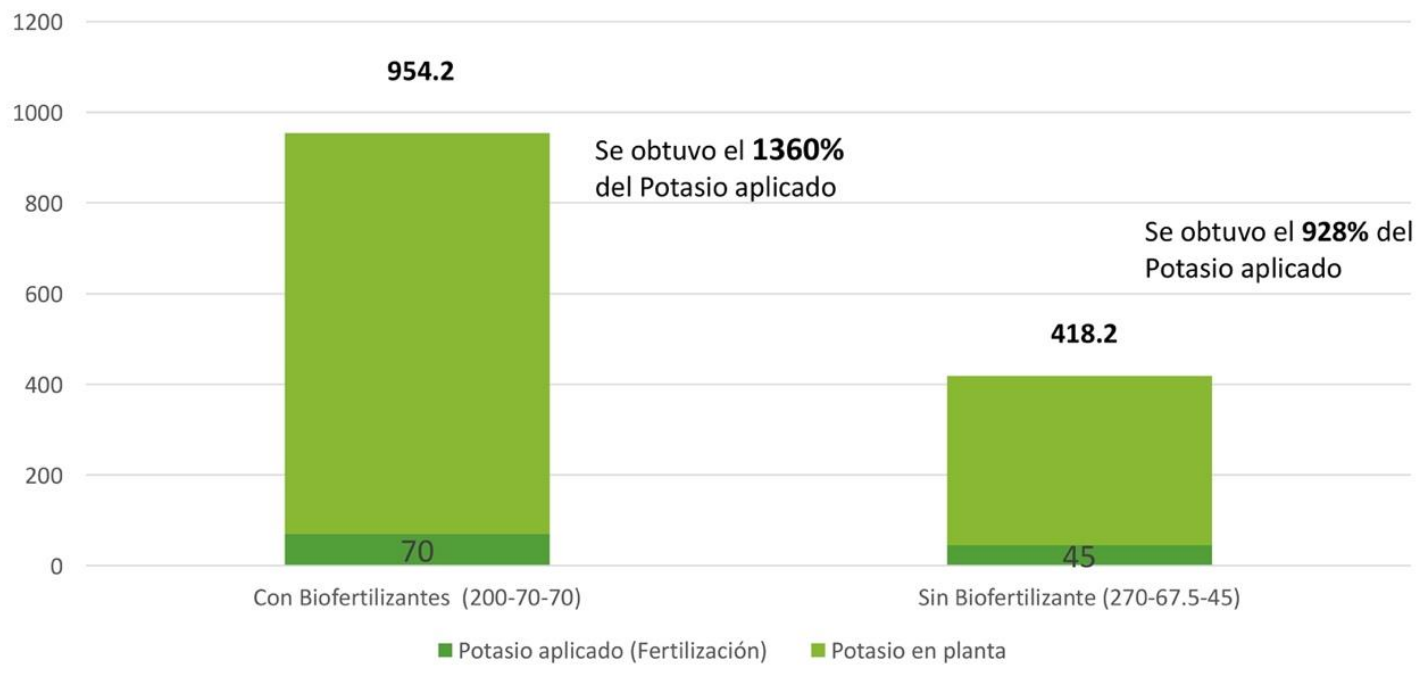

Fuente: Elaboración propia. 


\subsection{Resultados en la regeneración del suelo}

\subsubsection{Abundancia y diversidad microbiana}

Este parámetro se analizó determinando las bacterias cultivables y diferenciando los morfotipos diferentes de colonias bacterianas, por lo que, a pesar de no ser un reflejo fiel de la diversidad y abundancia de estos microorganismos en el suelo, sí nos permite comparar diferencias entre los microorganismos de ambos tratamientos, tal como se puede observar en la gráfica 7, con una diferencia de 14 morfoespecies bacterianas y más de un $100 \%$ de Unidades Formadoras de Colonias (UFC) bacterianas por gramo de suelo (de 8.6 millones en el testigo a 17 millones en el tratamiento con biofertilizantes).

Gráfica 7. Diversidad y abundancia microbiana.

DIVERSIDAD Y ABUNDANCIA BACTERIANA TOTAL
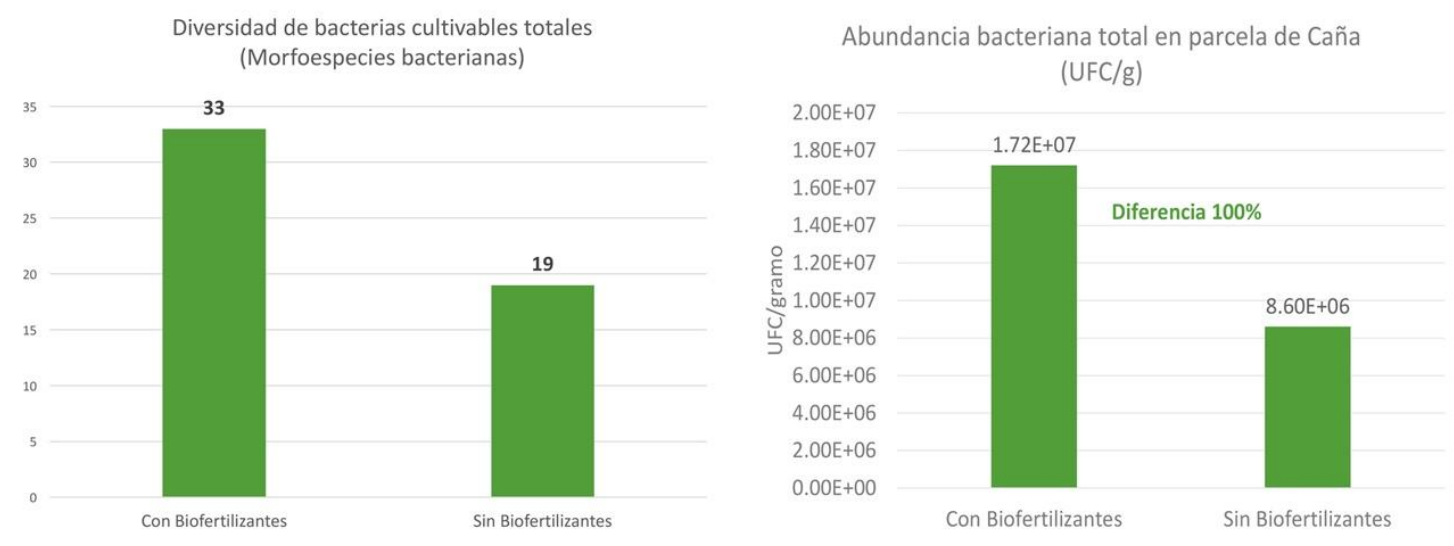

Fuente: Elaboración propia.

\subsubsection{Glomalina}

Otro parámetro importante en donde se encontró una diferencia significativa es en el contenido de glomalina del suelo (ver gráfica 8). La glomalina es una proteína producida por los hongos micorrízicos, que sirve como pegamento para las partículas del suelo. Su función es pegar las partículas finas (micro agregados) y así formar partículas mayores (macro agregados). Estos macro 
agregados son los que le dan la estructura porosa al suelo que permite que se infiltre y retenga el agua, y que circule el aire. Además, ayudan a conservar la materia orgánica del suelo, mejoran la capacidad de intercambio catiónico, protegen a los microorganismos benéficos del suelo y facilitan la solubilización de minerales.

Gráfica 8. Glomalina del suelo.

Glomalina en el suelo de parcela de caña con 7 años de uso de Biofertilizantes

(kg/ha)

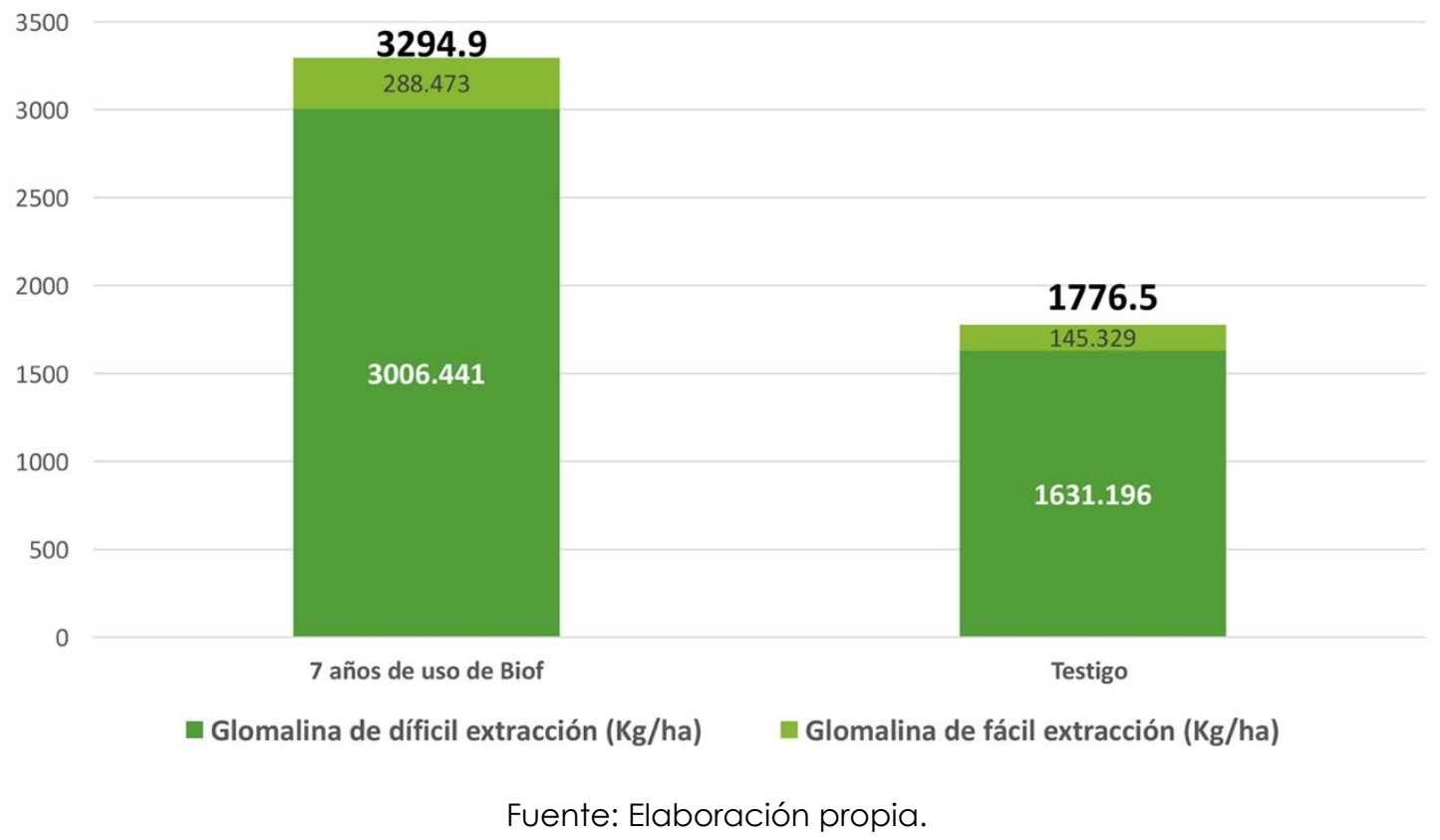

\subsubsection{Estructura del suelo (micro y macro agregados)}

Como se mencionó anteriormente, los agregados del suelo son las partículas que le dan estructura porosa e intervienen en diversos aspectos relacionados con la fertilidad. Además, se considera que la glomalina es uno de los componentes principales que permiten la formación de macro agregados a partir de los micro agregados. Esto puede relacionarse directamente con el contenido de agregados del suelo, ya que como puede observarse en la gráfica 9, se encontró un 15\% más de macro agregados en el tratamiento con biofertilizantes. 
Gráfica 9. Porcentaje de agregados estables en agua.

Porcentaje de agregados estables en agua

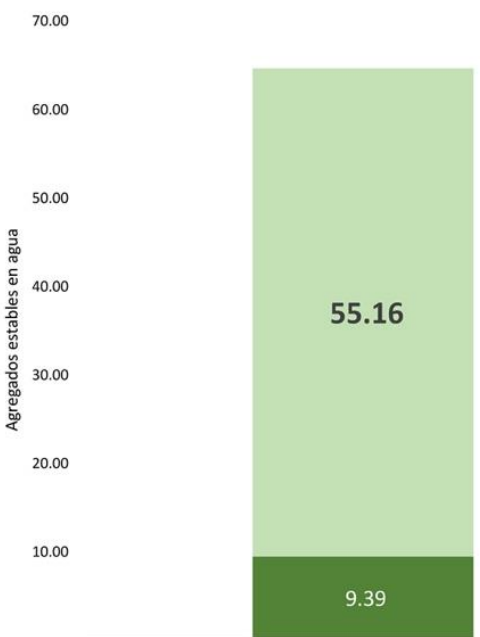

Con biofertilizante

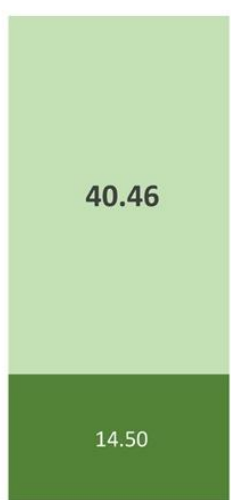

Sin biofertilizante
Macroagregados

nicroagregados

Fuente: Elaboración propia.

\subsection{Resultados de los beneficios ecológicos}

\subsubsection{Incremento de materia orgánica}

Con respecto al contenido de materia orgánica del suelo, calculado a partir de análisis de suelo realizados por laboratorios certificados, también pudo observarse un incremento sucesivo en los últimos tres años de seguimiento del tratamiento con biofertilizantes (ver gráfica 10). Este incremento en la materia orgánica puede explicarse a partir del incremento en la biomasa radical y del incremento en la actividad microbiana del suelo. 
Gráfica 10. Contenido de materia orgánica en el suelo en parcela de caña a los 5, 6 y 7 años de uso de biofertilizantes.

Contenido de Materia orgánica de parcela de caña con 5, 6 y 7 años de uso de Biofertilizantes (ton/ha)

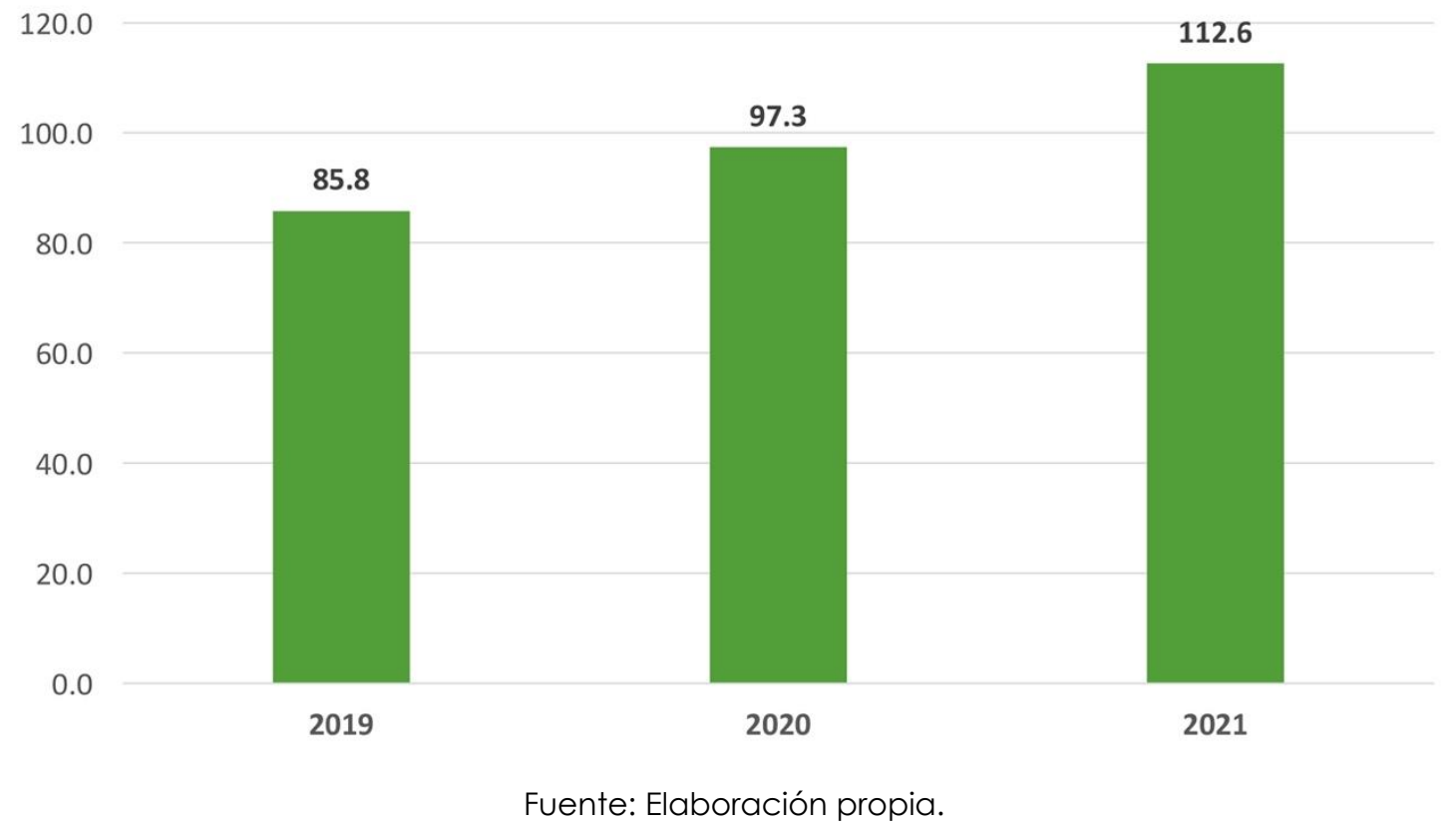

\subsubsection{Secuestro de carbono}

Otros de los efectos que impactan directamente sobre la mejora en la sustentabilidad y el medio ambiente de los biofertilizantes, es el aumento en la capacidad de secuestro de CO2 atmosférico en los suelos. Como se puede ver en la gráfica 11, con el uso de biofertilizantes se logra una importante captura de carbono en la parcela, y se demuestra un efecto acumulativo que potencia esta capacidad en el suelo. 
Gráfica 11. Secuestro de carbono en el suelo en parcela de caña a los 5, 6 y 7 años de uso de biofertilizantes.

\section{Carbono total (ton/ha)}

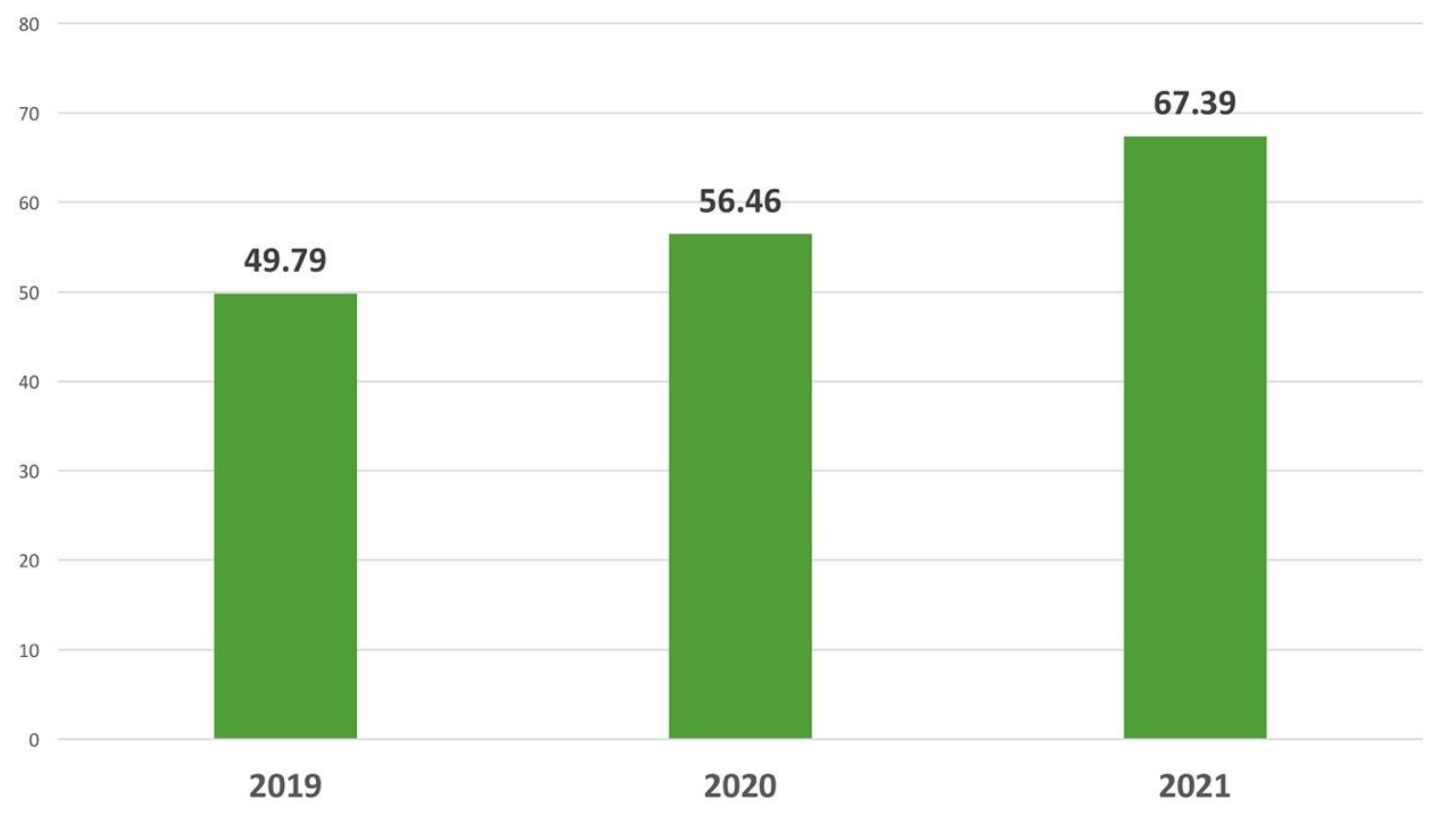

Fuente: Elaboración propia.

\section{CONCLUSIONES}

El sistema de producción presentado en este artículo, basado en el uso de insumos agrícolas de origen biológico, permiten disminuir significativamente el uso de agroquímicos, reduciendo al mínimo su impacto en el suelo y cuerpos acuáticos, así como la contaminación atmosférica.

Además, este sistema estimula la recuperación y regeneración de las condiciones físico, químicas y microbiológicas del suelo, así como una mayor captura de carbono, contribuyendo a mitigar el cambio climático. Cabe resaltar que todos estos efectos positivos comienzan a verse a los pocos días de la aplicación de los biofertilizantes, pero que, como se ha demostrado con la evaluación y seguimiento de varios ciclos, dichos efectos son acumulativos y potencian los resultados positivos en un corto y mediano plazo.

Por último, se concluye que el sistema de producción propuesto en este estudio, aporta enormes beneficios para los productores y sus familias, así como 
para las personas, empresas e industrias involucradas en el proceso de obtención de azúcar y otros productos, a partir del cultivo de la caña.

\section{REFERENCIAS}

CAMARGO-RICALDE S. L., MANUEL M. N. DE LA ROSA-MERA C. J. Y MONTAÑO A. S. A. (2012). Micorrizas: una gran unión debajo del suelo. Revista Digital Universitaria. 13(7): 3-19. http://www.revista.unam.mx/vol.13/num7/art72/art72.pdf

FALCÓN M. (2018). El trabajo decente en la agricultura de caña: alcances y desafíos para la sustentabilidad. México. http://www.atamexico.com.mx/wp-content/uploads/2018/11/5.ADMINISTRACI\%C3\%93N-XL.pdf

GRAGEDA O., DÍAZ A, PEÑA J. J. Y VERA J. A. (2012). Impacto de los biofertilizantes en la agricultura. México. http://www.scielo.org.mx/scielo.php? script=sci arttext\&pid=s2007$\underline{09342012000600015}$

GUERRA S. B. E. (2008). Micorriza arbuscular. Recurso microbiológico en la agricultura sostenible. Tecnología en marcha. 21(1): 191-201. https://revistas.tec.ac.cr/index.php/tec marcha/article/view/1352/125 $\underline{4}$

LICEA-HERRERA J. I., QUIROZ-VELÁSQUEZ Y HERNÁNDEZ-MENDOZA J. L. (2020). Impacto de Azospirillum brasilense, una rizobacteria que estimula la producción del ácido indol-3-acético como el mecanismo de mejora del crecimiento de las plantas en los cultivos agrícolas. Rev. Bol. Quim. 37(1): 34-39. http://www.scielo.org.bo/pdf/rba/v37n1/v37nl_a05.pdf

REYES M. (2011). La agricultura de la Revolución Verde a la Revolución Sostenible. México. https://www.eleconomista.com.mx/opinion/Laagricultura-de-la-Revolucion-Verde-a-la-Revolucion-Sostenible$20110907-0005 . h t m l$

TORTORA G. J., FUNKE B. R. Y CASE C. L. (2007). Introducción a la Microbiología. $9^{a}$ edición. Editorial medica panamericana. Buenos 
Aires, Argentina.

https://books.google.com.mx/books?id=Nxb3iETuwplC \&printsec=front cover\&da=Introducci\%C3\%B3n+a+la+Microbiolog\%C3\%ADa\&hl=es\&sa $=X \&$ redir $e s c=y \# v=o n e p a g e \& q=a z o s p i r i l l u m \& f=f a l s e$

OMS

https://www.who.int/features/qa/87/es/\#: :text=Los\%20productos\%20 qu\%C3\%ADmicos\%20peligrosos\%2C\%20como, (pueden\%20da\%C3\%Bla r\%20al\%20feto).

Biofábrica Siglo XXI

http://www.biofabrica.com.mx/

Bonsucro

https://www.sgs.mx/es-es/sustainability/environment/energyservices/alternative-fuels/bonsucrocertification\#: : text=Sostenibilidad\%20Certificaci\%C3\%B3n\%20Bonsucr o\&text=La\%20certificaci\%C3\%B3n\%20Bonsucro\%20ofrece\%20una, sumin istro\%20satisfacen\%20estos\%20requisitos\%20estrictos.\&text=El\%20est\%C 3\%A Indar\%20Bonsucro\%20ha\%20recibido, satisfacer\%20los\%20requisitos \%20de\%20sostenibilidad.

Gobierno de México - Blog de la Secretaría de Agricultura y Desarrollo Rural. https://www.gob.mx/agricultura/es/articulos/cana-de-azucar-unadulce-produccion-237168

Universidad Zaragoza

http://www.unizar.es/centros/eps/doc/HuelladeCarbonoLALGranadas ept2010 d.pdf

Ley de Desarrollo Sustentable de Caña de Azúcar - Diario Oficial de la Federación, 22 de Agosto, 2005. http://extwprlegs 1.fao.org/docs/pdf/mex69602.pdf 
C3-BIOECONOMY, Revista de Investigación y Transferencia en Bioeconomía Circular y Sostenible N² (2021) 